Capítulo 6 



\title{
Los retos de la articulación entre cultura escolar y cultura mediática
}

\author{
Víctor Hugo Garcés*
}

Cuando los medios y las nuevas tecnologías comenzaron a ingresar al escenario escolar, se desarrollaron dos modos de ver el fenómeno: por un lado, se comenzó a interpretar la aparición de móviles, nuevas prácticas de aprendizaje, la información y el entretenimiento como una amenaza para el proceso educativo; por el otro, se comprendieron las nuevas tecnologías educativas (tecnologías de la información y la comunicación [TIC]) como instrumentos que, por sí solos, y con su uso como única condición, modernizan tanto la escuela como las prácticas docentes.

La generalización de esta doble perspectiva permitió que las instituciones educativas desconocieran los verdaderos alcances de la relación entre la vida escolar y las prácticas mediáticas. Este tipo de interpretaciones ha arrojado a los educadores y directivos docentes a desarrollar no solo estrategias normativas y disciplinarias encaminadas a la expulsión de cualquier tipo de dispositivo móvil que pueda perturbar la concentración del educando o trastocar el flujo tradicional del conocimiento, sino también una lógica de modernización del sistema escolar basada en la gestión de la transferencia tecnológica y la capacitación técnica necesaria para su uso. Esto ha hecho que se oculten los retos y las transformaciones que las integraciones de la cultura mediática a la cultura escolar han traído a la escolarización y la alfabetización del sujeto contemporáneo.

Según Barbero (1999), las prácticas mediáticas están descentrando y desreglamentando el flujo de los saberes y las jerarquías del aprendizaje. La vida mediada por los medios se está ampliando, a manera de integración, al lugar de

\footnotetext{
* Licenciado en Educación Básica con Énfasis en Ciencias Sociales de la Universidad Distrital Francisco José de Caldas. Magíster en Comunicación-Educación de la Universidad Distrital Francisco José de Caldas. Docente de la Facultad de Ciencias y Educación de la Universidad Distrital Francisco José de Caldas.
} 
la experiencia de aprendizaje y al recorte cultural de conocimientos y competencias (el currículo escolar) que implicaba la inmersión en la cultura escolar. El sujeto escolarizado, al entrar en la cultura mediática, está presenciando una nueva economía del tratamiento de la alfabetización, de la adquisición de las representaciones, de la retención de la memoria y del soporte intergeneracional del conocimiento (Rueda, 2012b), que se articula, vía sujeto, con los escolares.

La emergencia las prácticas mediáticas, y su ensamblaje a la vida escolar, generó "una pedagogía permanente" (MacLaren, citado en Huergo, 2001): la articulación del "conjunto de prácticas, saberes y representaciones producidas y reproducidas a partir de la institución escolar" (Huergo, 1998, p. 50) con "la capacidad modeladora del conjunto de prácticas, saberes y representaciones sociales que tienen los medios y las tecnologías de la información" (Huergo, 2001, p. 88). Dos ámbitos educativos forman una continuidad que, desde el interior de la cotidianidad de los sujetos, afecta el pensamiento, los procesos de alfabetización y, con fines disciplinarios y de control del cuerpo, las técnicas de escolarización e individualización, respectivamente.

De ahí que esta continuidad pedagógica esté operando, desde los hábitos y costumbres de los sujetos escolarizados, en ámbitos y lugares distintos (espacio-tiempo escolares y extraescolares), y sobre objetos distinguibles (el cuerpo y los pensamientos del sujeto), con el fin de controlar la producción de los sujetos y las subjetividades. Más que una pugna radical entre los medios y las nuevas tecnologías y los procesos educativos escolares, existe una integración, articulación y compatibilidad progresiva, dada por la continuidad de las dos formas masivas de producción, transmisión y reproducción de la vida social cotidiana.

Las rupturas de la cultura mediática y la vida escolar con los sujetos contemporáneos no se deben a su incompatibilidad o a su pugna con la escuela y su pretensión de hegemonía de la adjudicación de la vida cultural y política; por el contrario, aluden a conflictos y contradicciones que representan otros tantos antagonismos y oposiciones con las sociedades a las que conciernen (Huergo, 1998). Es en la falta de representatividad social de la cultura escolar que los sujetos entran en pugna con sus prácticas escolares, y es en la incapacidad de integrar y dominar las técnicas del tratamiento de los signos y los símbolos que la cultura mediática avasalla con su imposición. Más se trata de la incompatibilidad de dos modos de imposición cultural con las sociedades que son su objeto, que de la ruptura entre ambos espacios-agencias educativos. 


\section{El marco de la articulación cultura escolar-cultura mediática: de la ruptura con la Modernidad a la continuidad con las formas culturales, económicas y políticas posmodernas}

Para algunos autores, la aparición de mediaciones técnicas, la transformación y surgimiento de tecnologías y aparatos causan la ruptura con las formas culturales, económicas y políticas anteriores. Según esta visión, la emergencia del espacio virtual y de los nuevos hábitos de información y comunicación trajeron consigo transformaciones socioculturales, mutaciones de los modelos políticos y económicos, y cambios de las maneras de estructuración de la percepción y de la economía de los significados, irreconciliables con el mundo del cual emergen.

A la organización progresiva, razonada, jerárquica y compiladora de la enciclopedia se le opondría, según Lévy: "una mutación técnica donde la inteligencia adquiere un carácter participativo, socializante, abierto y emancipador" (Rueda, 2012b, p. 14). De las secuencias de aprendizaje por edades, etapas y especialidad complejas complementarias, se pasaría a "una suerte de incapacidad de adoptar un único y fijo punto de vista con respecto a la realidad, y, a la vez, a "la posibilidad de enfocar la realidad desde muchos puntos de vista diferentes, simultáneamente" (Huergo, 1998, p. 51). De las culturas ligadas al territorio, se transitaría a un reparto masivo de los bienes culturales, a una dialogicidad multidireccional de las culturas en el ciberespacio y la emergencia de colectividades de sentido (Gómez, 2005) (en principio atadas a códigos colectivos que fluyen en los discursos y los géneros musicales).

A las mediaciones políticas democráticas que, bajo su forma delegación y representatividad, se centraban en la participación en las decisiones del Estado, por medio del voto y los partidos políticos, les seguiría el surgimiento de una "democracia semiótica", que desplazaría el ejercicio de la ciudadanía hacia una esfera pública (Winocur, 2007; Keane, 1997) y un sistema de comunicación estatal (Collado, 2008; Easton, 1969). De la economía centrada en la fábrica y sus relaciones sociales, se transitaría a una economía mundial descentrada por los flujos de información y comunicación (Castells, 2006), que dilataría y redistribuiría la tensión entre clases.

Pero, por el contrario, se observa que al proceso de retroalimentación comunicativa del sistema estatal democrático se ha integrado un sistema ciudadano de comunicación autónoma y autogestionada (por ejemplo, las radios comunitarias o ciudadanas), que ha complementado el ejercicio del voto y la representación con la mutación de las prácticas de comunicación política regional, efecto del equipamiento tecnológico de la participación ciudadana. Estas comunidades no se distancian de las prácticas de autoridad y decisión que le 
circundan y determinan, desplazando sus discursos hacia el ciberespacio de la "democracia semiótica", sino que combinan la acción política local con prácticas nacionales y globales de resistencia y propaganda política. No dejan de exigir a la gobernanza respuesta a sus necesidades y problemáticas, sino que usan el medio para maximizar las conciencias y la presión a los gobernantes y representantes; incluso, llaman a rendir cuentas al gobierno local y movilizan acciones nacionales y globales.

Algo similar está pasando con las nuevas formas de la economía mundial. Estas se ensamblan con sistemas nacionales ordenados para suplir las necesidades modernas heredadas de siglos anteriores. Las sociedades posindustriales, y sus redes empresariales, aún necesitan los recursos del tercer mundo, y, en oposición, cada país propende, en primera instancia, por suplir sus necesidades nacionales. Una contradicción entre el proteccionismo y el mercado mundial emerge a modo de sistema-mundo, centro-periferia (Wallerstein, 2007). Las interacciones y las comunicaciones empresariales sufren este efecto: las empresas no solo se amalgaman en una red multinacional, de equipamiento tecnológico y globalización de mercado, sino también necesitan del flujo de la información, los insumos, los productos y los trabajadores, a escalas nacional y local.

En lo referente a la cultura, tanto los residuos culturales no modernos ("cultura del común"), como los resultados y los procesos de alfabetización moderna (la alfabetización escolar), y los resientes resultados de las nuevas y múltiples alfabetizaciones modernas (la resultante de los medios y nuevas tecnologías de la sociedad de la información), coexisten en las sociedades contemporáneas, y hasta en los mismos sujetos que son su objeto.

Por consiguiente, en la actualidad, vemos cómo las transformaciones que traen consigo los medios y las nuevas tecnologías registran especialidades, continuidad y sumatorias respecto al mundo anterior, y no desplazamientos espontáneos y radicales (Roncagliolo, 1997). Los procesos de la cultura mediática no se están viviendo por cuenta de los anteriores. Las relaciones mediadas por los medios no han acotado las interrelaciones no mediáticas, ni la humanización del entorno inmediatamente anterior a los avances en los aparatos y las técnicas ha dejado de existir; por el contrario, se entremezclan ambas en una complejidad cultural, económica y política que le da forma a la era actual. Sin lugar a dudas, hay un sujeto contemporáneo que está viviendo la transformación de las formas a través de las cuales se interrelaciona con el mundo que él ha creado, así como de los desplazamientos que trae consigo ir progresivamente centralizando la interacción social en los aparatos y sus inherentes tecnicidades. 


\section{La cultura escolar: la escolarización y alfabetización de los sujetos modernos. La sucesión del cuerpo y la normalización del pensamiento}

La cultura moderna surge en Occidente, centrada en la cultura escolar como espacio transitorio de la barbarie a la civilización, de la minoría de edad a la ilustración. La escolarización, en cuanto cultura en sí, es uno de los núcleos que permitió, en paralelo con la alfabetización, la inserción de las personas, los grupos y las sociedades en los rasgos propios de la Modernidad: la sociedad capitalista, la cultura de masas, el Estado moderno, la forma físico-matemática de proyectar la realidad, entre otros. Y es de esta manera que "la escuela se va constituyendo como una institución destinada a producir un determinado orden imaginario social y a reproducir las estructuras y organizaciones modernas existentes" (Huergo y Fernández, 2000). Es a través de la forma de vida escolar que se pasó -y en cierta medida se sigue pasando- de la barbarie de otras culturas a la constitución del sujeto civilizado moderno.

Pero esto solo ha sido posible en la medida que la escuela permite operar, desde su espacio, sobre los cuerpos y, como ámbito educativo, sobre el pensamiento, pues el individuo se escolariza para poder moldear su comportamiento; su pensar se alfabetiza para poder coordinar con las necesidades de la sociedad. Es decir, que el modo de vida escolar, poco a poco, normaliza cultural y políticamente a los sujetos.

En efecto, la función escolarizante, en tanto primera ocupación de la escuela, consiste en el moldeado y normalización de los sujetos en formación, efecto de su inmersión en una cultura de distinción y reproducción social. Esta función es una máquina cultural que opera sobre la disciplina; que obliga a educarse en un espacio determinado, con unas prácticas específicas. Así, el sujeto se convierte en objeto de todo un método penitenciario.

De un lado, se pensó, y se sigue pensando, el espacio escolar en función de la distribución de los cuerpos y las características de los lugares destinados a la realización de determinadas actividades y rutinas. Del otro, la institución escolar definió un estatuto de la infancia, el joven como sujeto violento, delincuente, desviado socialmente, incorregible, que se debe preparar para el futuro.

Por lo tanto, la función escolarizante del sistema escolar se puede equiparar con lo que Foucault llamó la "forma-prisión": una de las instituciones donde se elaboran y ponen en acción los procedimientos para repartir a los sujetos, ubicarlos y distribuirlos en el espacio, "clasificarlos [...] educar sus cuerpos, codificar su comportamiento continuo [...] formar en torno a ellos todo un aparato de observación, de registro y de notaciones, construir sobre ellos un saber que se acumula 
y se centraliza" (Foucault, 1976, p. 265); "un cuerpo de especialistas dotados de técnicas, tecnologías específicas y códigos teóricos" (Huergo y Fernández, 2000, p. 87); una maquina impersonal que constituye al individuo moderno, al convertirlo en producto de "las formas de relación entre el sujeto y la verdad, las formas de gobierno de los sujetos y las formas en que son dispuestos en relación consigo mismos" (Obregón, 2009, p. 52).

En la medida que la escuela sigue siendo, y se continua entendiendo, como un dispositivo de normalización del comportamiento de los individuos, el sujeto confinado a la vida escolar está expuesto a toda una serie de instancias punitivas que, para su administración, cristalizan formas de administración jerárquica. El sujeto, en este espacio cultural, está, persuadido por la dosificación especializada de los procederes, las actitudes, los valores, las aptitudes convivenciales, entre otras máximas culturales; está limitado por una normatividad especifica (leyes educativas, manual de convivencia, normas de clases, una moralidad determinada, entre otras reglas); está coaccionado por un conducto regular y unos soportes de notación judicial (el cuaderno, el boletín, el observador del estudiante, los compromisos académicos y de convivencia, entre otros); cohibido por la jerarquía de los agentes educativos (los docentes, orientadores, coordinadores, consejos, entre otros posibles) y la estructura del sistema escolar (organización jerárquica o relaciones de poder de cada colegio); inclusive constreñido por la interacción significante con sus pares. Está inmerso en un modo de vida estructurado para moldear su comportamiento.

Del otro lado del fenómeno, la institución escolar se diseña para, desde el proceso de enseñanza-aprendizaje, cumplir una función alfabetizante sobre el pensamiento y el comportamiento. Se entiende la escuela como un proceso de "control pedagógico" que "transforma, o perpetúa, desde dentro de la cotidianidad social, las representaciones simbólicas y los referentes de organización social" (Huergo y Fernández, 2000). Con la creación de esta vida escolar destinada a la educación de los niños (en su pugna con otros modos de educación), se permitió, por un lado, imponer una modalidad de apropiar-usar el conocimiento - un control instructivo legítimo, centrado en la cátedra, la escritura y la lectura, como técnicas de la cultura "letrada", y formas de la memoria y del tratamiento de los contenidos, que recorta, controla y organiza, por edades, etapas y materias, los saberes, las representaciones y las capacidades que el sujeto debe aprender- y, por el otro, una habituación para funcionar en la cotidianidad - un contenido normativo para pensar y actuar con otros, y un ajuste y preparación del sujeto para ejercer un rol, asignado $\mathrm{u}$ adquirido, en relación con el sistema político-económico.

Pero, a pesar de esto, la cultura escolar es también un espacio público de formación política y de construcción de ciudadanía, "donde es posible identificar una indisciplinada voluntad de formación crítica" (Huergo, 1998, p. 52). La vida escolar se presenta como una microesfera pública, un lugar de encuentro masivo 
y durable, de reunión de los niños, jóvenes y adultos, un espacio de apropiación de las prácticas políticas (modalidades de participar y maneras de pertenecer), de formación de la opinión y los sentidos de la acción política, pero también un escenario en el que entran en pugna con la hegemonía de las otras posturas políticas ideológicas las enraizadas narrativas culturales (orales, prosódicas, quinésicas, corporales, o la adopción de determinados adornos), las ancestrales y nuevas coordenadas de ser y de actuar, individual o de manera colectiva, en sociedad.

De ahí que la cultura escolar ha sido una modalidad dominante de comunicación donde se instruye sobre las prácticas, las representaciones, los discursos, los conocimientos y los saberes necesarios para actuar de forma política en determinada sociedad, a la vez que un ejercicio de la ciudadanía y la política, en el cual se da el debate sobre el poder y el "reconocimiento de los sujetos y los saberes que se fraguan en las historias hendidas relaciones de poder diferencialmente constituidas" (Huergo, 1998, p. 56). Sin embargo, a pesar de que la institución escolar opera sobre la gran mayoría de los sujetos, no es la única que transmite la cultura y genera formas políticas entre los individuos. El sujeto contemporáneo también se ve inmerso en otras formas culturales que operan masivamente, en otros tiempos y espacios de la experiencia, sobre el cuerpo y el pensamiento. Una de esas formas es la cultura mediática - quizá la que, después de la escuela, tiene más influencia sobre los individuos en la actualidad.

\section{La integración de la cultura mediática a la vida escolar contemporánea: la ampliación del disciplinamiento del cuerpo y la degradación de la alfabetización del pensamiento}

La cultura escolar y la cultura mediática, como procesos distintos, pero no contradictorios, se están integrando, articulando y complementando a modo de "una pedagogía permanente" (MacLaren, citado en Huergo, 2001). Mientras que la alfabetización letrada hace posible, en la vida escolar, "una clase de autorreflexión, autorrepresentación que se traduce en una forma de considerar la vida, de comportarse en el mundo, de actuar y relacionarse con otras personas" (Rueda, 2012, p. 47), las alfabetizaciones posmodernas, propias de los medios y las nuevas tecnologías, están produciendo "una suerte de incapacidad de adoptar un único y fijo punto de vista con respecto a la realidad, y, a la vez, la posibilidad de enfocar la realidad desde muchos puntos de vista diferentes, simultáneamente" (Huergo, 1998, p. 51).

Como resultado, en una primera instancia, la integración de la cultura mediática a la vida de los sujetos escolarizados está generando ajustes, movimientos y ampliaciones a la cultura escolar. Si bien los individuos siguen destinando un 
considerable tiempo de su vida a la escolarización, sus prácticas educativas también se están extendiendo, de manera consiente o no, en determinada inversión de tiempo, a la interacción con los medios y las nuevas tecnologías. Diferentes instancias de la percepción y disímiles procesos de negociación de significados influyen en diferentes espacios y momentos de la educación del sujeto.

Esto hace que los niños y jóvenes en formación estén migrando y retornando, en diferentes momentos vitales, de los procesos de enseñanza y aprendizaje propios de la lógica escolar a la practicas mediáticas extraescolares. De un lado, el sujeto escolarizado, además de ser expuesto a la cultura escolar, es influenciado, directa o indirectamente por "la capacidad modeladora del conjunto de prácticas, saberes y representaciones sociales que tienen los medios y las tecnologías de la información" (Huergo, 2001, p. 50). Del otro, del mismo modo que sucede con las interacciones educativas en el aula de clase, los individuos aprenden en su casa, frente al televisor o cerca a la radio, mientras leen los periódicos o usan su computadora para acceder a la educación a distancia o a información de su interés; pero también cuando usan los aplicativos de sus móviles, en el transporte o en lugares con otros propósitos.

En segunda instancia, las prácticas educativas y los métodos de enseñanza que se hacen permanentes en el cotidiano escolar-mediático de los sujetos están produciendo la ampliación progresiva, a modo de sumatoria, de la alfabetización escolar hacia la vida mediática.

En una primera etapa, se está ampliando el escenario de aprendizaje a diferentes instancias de la aprehensión de significados. El sujeto contemporáneo está viviendo la producción y consumo de objetos virtuales de aprendizaje (los videos de YouTube, los videojuegos con temáticas históricas, entre otros), los cuales, fuera de las viejas y limitantes herramientas tecnológicas de la escuela (el tablero, los documentales, los libros de texto, las fichas de imágenes temáticas, entre otras), bien sea en el marco de la educación a distancia o en los ámbitos de negociación hipertextual o imposición programática de conocimientos y saberes, terminan por retroalimentar u oponerse al recorte cultural impartido en la escuela.

En una segunda etapa de esta ampliación de la alfabetización escolar a otras mediaciones, los alumnos se están integrando en diferentes comunidades de sentido o comunicación, y en rituales de audienciación, que generan y reproducen saberes paralelos al escolar (como el reconocimiento y la apropiación de los valores y saberes propios de las culturas urbanas). Los educandos están educando a sus pares a través del uso de las nuevas tecnologías (los youtubers estudiantes), a la vez que ambos participan en foros o reflexiones que fungen como ámbitos de negociación de los sentidos de la realidad (foros especializados, opiniones expresadas a través de emoticones, memes, fotos, comentarios o videos expuestos en las redes sociales, 
entre muchas otras), que luego integran, vía subjetividad, a la escuela, bien sea como opinión, creencia o presaber aceptado en grupo.

Ahora bien, indirecta o directamente, la circulación y el flujo de saberes, conocimientos, representaciones y múltiples puntos de vista en la vida mediada ha tomado a los sujetos como vehículos para insertarse a las luchas discursivas que se dan en las entrañas mismas de la escolaridad. Los docentes, en la construcción y programación de unidades de conocimiento - organizadas, lineales y secuenciadas, propias de la lógica escolar-, integran contenidos de diferente índole, alojados en la red de aparatos (bien sean audiovisuales, o artículos sobre determinados temas, entre otros) que, en cierta medida, transforman los conocimientos que se estipularon y jerarquizaron en los libros de texto para la edificación de los currículos. De modo complementario, los estudiantes, en su afán por encontrar información que resuelva sus tareas, consignan en sus notas lo primero que les arrojan los motores de búsqueda, llevando, de esta manera, conocimientos contradictorios o saberes que robustecen el punto de vista transmitido en el aula.

Por su parte, la ampliación de los límites del espacio específico para la educación de los niños y los jóvenes, gracias a la creciente posibilidad de elección (online y offline); la libertad de contenidos (la posible evasión de la enseñanza programada y del libro como únicos depositarios del saber universal), y la integración de las nuevas tecnologías al aula de clase están haciendo que se degrade, hasta desaparecer, la mediación instructiva. Estamos presenciando la producción y el consumo de objetos virtuales de aprendizaje (los videos de YouTube, los videojuegos con temáticas históricas, entre otros), los cuales, fuera de las viejas y limitantes herramientas tecnológicas de la escuela (el tablero, los documentales, los libros de texto, las fichas de imágenes temáticas, entre otras), bien sea en el marco de la educación a distancia o en los ámbitos de negociación hipertextual o imposición programática de conocimientos y saberes, terminan por retroalimentar u oponerse al recorte cultural impartido en la escuela.

Asimismo, la integración de la cultura mediática a los procesos de alfabetización escolar está degradando y desquebrajando el control que ejerce el cuerpo docente en el proceso educativo (mediación del conocimiento), pues el docente ya no está teniendo el dominio total de los saberes y de las prácticas que le permitían monopolizar la instrucción escolar. La integración de los aparatos móviles personales al aula de clase, y, con estos, el uso de aplicaciones de mensajería instantánea están embargando la concentración de los alumnos y los flujos del saber; están sirviendo como circuito de escape a la instrucción. El educando, cuando convierte el salón en un lugar más de interacción virtual, está imposibilitando, con sus prácticas mediáticas, que el proceso de transmisión masiva de conocimientos se realice; el acceso instantáneo a las temáticas escolarizadas, a través de los dispositivos móviles, le permite al estudiante contrastar, complementar u oponer la información hallada a la que el docente pretende impartir. 
Asimismo, la integración de la cultura mediática a la vida escolar está desarreglando el "estatuto de la infancia": el niño y el joven, como sujetos presociales de cuidado, están en formación. La integración de los medios y las nuevas tecnologías a la vida del sujeto escolarizado está haciendo que los niños y los jóvenes se ubiquen en una dualidad estatutaria de la infancia, pues migran de su estatuto de ingenuidad e ignorancia, en la escuela, a un estado de 'pares' de los adultos, dada la liberación de la mediación pedagógica.

Las múltiples relaciones que posibilitan los medios ponen en funcionamiento roles y estatutos diversos de un mismo sujeto. Las nuevas tecnologías están generando la posibilidad de reinventar la historia personal (dar clic afirmativo a la pregunta por su mayoría de edad o crear un avatar, entre otras), según el interés y la conexión que se esté tramitando. El sujeto niño está teniendo la capacidad de publicar la experiencia vivida (mostrarse como es ante un público desconocido o como quiere ser) y de acceder a contenidos restringidos a su condición (tanto propios de los adultos, como ajenos a su prediseñado rol social). Así, los niños y los jóvenes, a medida que se adentran en los medios y las nuevas tecnologías, se liberan de la rigidez de la cultura escolar (en los tiempos de vida no escolar o en la integración de la cultura mediática en esta), y pasan a recibir la influencia de otras instancias de socialización y subjetivación cultural y política, distintas pero complementarias a la escolarización.

En definitiva, la extensión de la alfabetización a una economía de la educabilidad, como se expresó en líneas anteriores, está permitiendo que el pensamiento se alfabetice en múltiples mediaciones y con diversas perspectivas. La deslocalización de la escolarización le permite al individuo liberarse, a medida que sale de la cotidianidad escolar, del emplazamiento del cuerpo en el espacio analítico y de los procedimientos disciplinarios del maestro, para entrar en otro tipo de sujeción (contención, dominación o dependencia) corporal.

La continuidad de los procesos disciplinarios en la vida mediática, como expansión de la función escolarizante de la cotidianidad de la escuela, permite que la forma-prisión escolar se desmasifique, se individualice, bien sea en el ámbito doméstico o en la interacción intermitente con los aparatos durante la vida escolar. El sujeto, desde el equipamiento de su hogar y la portabilidad de sus dispositivos, se encierra en determinada inversión de tiempo al domicilio y hace posible una permanente conexión (en términos de posibilidad de integrarse al circuito) que lo individualiza del lugar de relación colectiva que se encuentra ocupando (cualquiera que este sea: la escuela, la oficina, la casa, el transporte...). En la vida escolar, por su parte, la incursión de equipamientos móviles ha posibilitado que el estudiante pueda escapar a otras interacciones comunicativas — aun inmovilizado en su pupitre-, como aquella maestro-conocimiento-alumno. 
Así, con la inversión del tiempo en el uso de los medios y las nuevas tecnologías de la comunicación, el entretenimiento y la información, el cuerpo se deslinda, en los momentos de conexión, de la mente; se transporta a un nuevo campo de la experiencia, a modo de inclusión o pugna con determinadas comunidades de sentido, y se aleja de los posibles máximos de relación colectiva del lugar social que está ocupando. Ya no es necesario que el individuo esté recluido en instituciones disciplinarias que operan sobre el cuerpo, pues las instancias de nuestra era posibilitan el control de su energía (cuerpo o pensamiento).

Esta capacidad de distribución del pensamiento en los circuitos del espacio virtual trae consigo, como consecuencia, el control de las interacciones colectivas, al ser distribuidas en este espacio-tiempo particular de interacción, y traducidas a códigos comunicativos y comunidades de semióticas, objeto de determinadas y determinantes técnicas; y, como causa, la inmersión del cuerpo en ciertos tipos de praxis comunicativas (lo sujetan, lo amansan y lo hacen dócil a fuerza de ejercicio y enseñanza), su reducción a mínimas expresiones de existencia. Así, la vitalidad, en estos hábitos de mediación, se traslada al pensamiento; se acostumbra a esta forma de existir, y se extiende a todos los momentos donde es posible.

Definitivamente, la continuidad de la integración escuela-cultura mediática está dada en la medida que estas operan, al ampliar el espacio disciplinar de la escuela, sobre los cuerpos, y, al continuar el proceso educativo, sobre el pensamiento. Y, sin embargo, la cultura mediática ha ampliado la posibilidad del ejercicio y la formación de la política y la ciudadanía más allá de las mediaciones políticas tradicionales y la vida escolar. La enseñanza de saberes para poder actuar en la vida política, el desarrollo de capacidades para pensar y actuar en determinado orden social, la vivencia de procesos de socialización y subjetivación política, y la posibilidad de crear realidades posibles y de actuar para transformar las existentes ya no están estrictamente ligados a sindicatos, partidos políticos ni a la vida escolar.

Es en los medios, y a través de las nuevas tecnologías, donde se ponen en escena determinados conceptos, conocimientos y saberes para el ejercicio de la ciudadanía; fluyen representaciones particulares del orden de tramitar y participar en la política (el Estado como ordenador social, la socialización de la política, entre otras); se vive una multiplicidad de relaciones que ponen en funcionamiento normas y reglas de interacción cotidiana; se reparten, a través de narrativas y discursos, percepciones, creencias y orientaciones en cuanto a la política en general, y en relación con el sistema político en particular, y, con la creación de la esfera pública mediática, se abre o cierra, en determinadas condiciones del espacio virtual, la posibilidad de intervención de la conciencia en el proyecto colectivo.

Con la emergencia de la cultura mediática aparecen nuevos espacios, hábitos, instituciones y costumbres del ejercicio de la política y la ciudanía que se integran 
y ensamblan, deteriorando los mecanismos de representación y transformación política existentes, pero, a la vez, avanzando hacia la formación individual de ideas, problemáticas y prioridades políticas (la ciudadanización de la política) (Lechner, citado en Winocur, 2007). A las tarimas para el discurso, la opinión y la discusión en el café literario; los debates e instrucciones sobre el poder y el saber en la escuela y las universidades; el performance de la oralidad, y la corporalidad que significaban la huelga y la marcha, entre otros lugares de la política, se sumó la posibilidad particular de una nueva relación espacial (ciberespacio) y de un escenario de debate (la interactividad discursiva), que surgen en paralelo con la emergencia de la esfera pública mediática y sus nuevas instituciones (la opinión mediada por los medios, la percepción colectiva, la inteligencia colectiva, las nuevas técnicas de acción a distancia (Lazzarato, citado en Rueda, 2012b). A los espacios confinados al encuentro político se sumaron los puentes interactivos que posibilitan los medios y las nuevas tecnologías, donde se observa, escucha o lee, o se puede discutir o intercambiar opiniones, de asuntos de interés colectivos de diversos grupos, desde el domicilio doméstico o la conexión desmasificada multimodal y multisitual que permiten los nuevos aparatos.

\section{Los retos de la pedagogía permanente: de la inhabilidad y la incapacidad inherente a las tecnicidades y las mediaciones contemporáneas}

La imposición cultural ha traído dinámicas ajenas a las capacidades y habilidades de los individuos inmersos en la cultura escolar y la cultura mediática. Si bien nuestras culturas no han dejado la centralidad de la sabiduría oral, se está presentando una transformación vertiginosa de los modos de leer y escribir el mundo (Huergo, 2001). No solo se lleva imponiendo, sin mucho éxito, la cultura letrada, y ahora la cultura polisémica, sino que emergen, inherentes a las nuevas tecnicidades y a las nuevas mediaciones, transformaciones en la transmisión, percepción y creación del conocimiento, y, con estos, trazos de la conciencia y la subjetividad que inhabilitan a los sujetos para la participación en todos los asuntos humanos.

A la pedagogía permanente, resultante de la continuidad de la escolarización y la inmersión en las mediaciones, se suman diversos espacios educativos, de diferente tipo e índole, que surgen como la trama de la formación. En una primera etapa, la escuela y los medios masivos electrónicos hacen énfasis en el contenido y en la unidireccionalidad de la transmisión de información, mediante un proceso que niega la réplica y la intervención del estudiante: una élite instruida (comunicador) enseña a una masa ignorante (oyente, receptáculo, depositario de información). Luego, en una segunda etapa, de manera incesante y complementaria con la anterior, se suman los tipos educativos en que los métodos de 
personalización e interacción, mediados por los aparatos, hacen énfasis en los efectos: una serie de fases donde un programador instruye (informa pero no forma) y motiva (condiciona, maneja y convence a través de la presión, repetición o motivación) al destinatario a modelar sus conductas y sus pensamientos (de no lograr el efecto esperado, reestructura el mensaje hasta que se generen la persuasión y el hábito) (Kaplún, 1998). En una tercera etapa, el educando, integrado a ámbitos de negociación de contenidos (foros, Facebook, Twitter, entre muchos otros), como parte de un método activo, y limitado por temáticas coyunturales y posibilidades hipertextuales, retroalimenta discursivamente, de manera inclusiva o excluyente, a una "comunidad de sentido, de afecto, de identidades" (Gómez, 2005, p. 331) de aprendizaje.

Lo que ha logrado la integración del sujeto en estos ámbitos educativos es un control instructivo permanente del conocimiento y la construcción de subjetividades inermes ante el proceso educativo y lo ocurrido en su entorno. Pero con la emergencia, como cuarto elemento, de la inteligencia colectiva y las transformaciones pedagógicas que han adelantado algunas corrientes educativas, tanto en la escuela como en las mediaciones, han emergido las condiciones necesarias para que se dé el ejercicio de una voluntad de formación crítica y reflexiva. Se han sumado a las capas anteriores espacios de resistencia a la unidireccionalidad del conocimiento, donde el educando se convierte en sujeto (se forma para transformar su realidad) mediante un proceso en el que el facilitador (profesor) hace, acompaña al otro (estimula el proceso de análisis y reflexión), y el sujeto aprende a hacer (razona por sí mismo), va descubriendo, elaborando y reinventando, aprende a aprender (instrumentos para pensar e interrelacionar) (Kaplún, 1998).

Así, con el diseño de los nuevos ámbitos educativos, en los lugares preexistentes, y las posibilidades de construir espacios mediáticos de educación alternativa, se ha anexado, a la trama de la formación subjetiva unidireccional, la posibilidad de participar en los contenidos, en el proceso educativo y en la transformación de la realidad.

Las modalidades de transmisión del conocimiento no son las únicas que han sufrido un proceso de complejización y acumulación; gracias a la integración progresiva del sujeto en la modelación de las alfabetizaciones, se ha reestructurado la economía técnica del tratamiento del conocimiento y la información en la sumatoria de capacidades de retención de la memoria, soportes intergeneracionales y tecnicidades prácticas de revisión y expresión del pensamiento (Rueda, 2012b). Debido a la integración del sujeto en la modelación de las alfabetizaciones modernas y posmodernas, emergieron nuevas tecnicidades que transformaron, de manera acumulativa, las condiciones y, en consecuencia, los procesos psíquicos donde tienen lugar los conocimientos. Al performance de la oralidad, y su capacidad de memoria viva y continuidad del discurso oral, se le sumaron, a modo de capas, primero, la capacidad de acumulación de las prácticas de escritura y lectura 
como expresión de la memoria humana y tratamiento analítico intergeneracional finito del tema, y, segundo, con la explosión mediática, una memoria en sí misma, limitada intergeneracionalmente por los tiempos de durabilidad de los circuitos que la integran. Dicha memoria, además, abrió paso al tratamiento hipertextual e intertextual polisémico de los asuntos humanos, a la influencia de la red temática, a la posibilidad de abordar la realidad desde muchos puntos de vista de forma simultánea, así como a la integración a estos métodos de un sistema de nexos sociales y sensibilidades que afectan los contenidos y sus flujos (Rueda, 2012b).

La inmersión del sujeto en la alfabetización moderna y posmoderna no solo reestructuró la economía del tratamiento del conocimiento, los saberes y la información, sino también puso a su disposición una ampliación de la economía de los recursos expresivos. En una primera transformación, al performance de la oralidad como medio de relación social que hace del hablante actor natural de la enunciación lingüística (convocando y orquestando naturalmente todos los lenguajes relacionados con el aparato fonador, el cuerpo y el espacio) se le sumó el uso de la escritura como principio discretizador y ordenador de las proposiciones, la razón y los discursos (Rueda, 2012b); una forma de comunicación menos ágil, espontánea y ligera, pero que invita al pulimento, a la precisión y a la reflexión (Roncagliolo, 1997) de lo consciente y lo comunicable, y el tratamiento iconográfico, simbólico, comunicativo, expresivo, estético, intersubjetivo, entre otros, que la pintura, la escultura y, después, la fotografía hacen de la realidad, de la subjetividad, y de otros fenómenos sociales y naturales.

Luego de La galaxia Gutenberg, en una segunda transformación, con la integración de los medios masivos electrónicos, se posibilita el uso - primero limitado y, luego, democratizado- de la oralidad radial, "constreñida al lenguaje verbal, carente de mímica y de gesto, mutilada de la expresión corporal, exonerada de la complicidad de las sonrisas y de la elocuencia de las miradas" (Roncagliolo, 1997, p. 4). Aquella, ante el laconismo del micrófono, desafía al hablante, de forma menos pausada y reflexiva, a hacer del verbo lenguaje total y, del sonido, ambiente complementario.

Más adelante, con el cine y la televisión, se fue ampliando la posibilidad de usar los utensilios audiovisuales, guiados por un tejido narrativo que prescinde solo del lenguaje táctil y olfativo en su ejercicio del poder de asedio y conquista (Charles Bally, citado en Roncagliolo, 1997). Finalmente, con la unificación y la interacción que posibilitan el uso de las nuevas tecnologías digitales, se procuró una nueva transformación, donde se genera una infraestructura multimedia interactiva, que abre su acceso a procesos de individualización colectiva, pero que suma y transforma todos los utensilios anteriores para efectos de una escritura hipertextual polisémica, que puede facilitar el uso pasivo (receptivo) o participativo (inteligencia colectiva) de múltiples lenguajes audiovisuales como medio de interacción comunicativa. 
Ahora bien, es en la resultante de estas transformaciones donde emerge la posibilidad de participar en la totalidad de las tramas de la transmisión, la percepción y la creación del conocimiento, y en estas, donde está la relación de la subjetividad del individuo con su producto y su productor social: la conciencia. Es en el contacto con las diferentes capas del conocimiento y la información donde el sujeto se hace consciente de sí y de los nexos limitados entre los que se debe relacionar con otras personas y cosas, pero, también, es con las posibilidades que abre la conciencia práctica - el lenguaje- que se crean realidades posibles.

En la oralidad fluyen, se retrasan y se plasman en la memoria humana las representaciones, narrativas o discursivas de cómo comportarnos ante lo concreto, o mejor dicho, ante los objetos y las relaciones tal como se presentan ante nosotros. Sin embargo, es con la inmersión del niño y del joven en la cultura letrada que la conciencia es susceptible de mayor reflexión y crítica, pero, además, de emanciparse del mundo sensible, entregándose al tratamiento de lo abstracto, y, así, de dedicarse a la creación intergeneracional e intersubjetiva de la representación de realidades posibles. Y es con la cultura electrónica que, a través de la oralidad secundaria, la hipertextualidad, la polisemia de la imagen y lo audiovisual, emerge la máxima potencialidad educadora de la comunicación del sujeto masivo y, con esta, la posibilidad más profunda de deconstrucción, construcción y mutación de las estructuras simbólicas, imaginarias, sensibles y representativas que fluyen en los contenidos modeladores del conjunto de la prácticas y experiencias que tiene la sociedad mediática.

Es en el uso de las modalidades educativas, las condiciones perceptivas y las situaciones creativas del conocimiento que se da, de un lado, el flujo y el retraso de la conciencia, y, del otro, el lugar donde la subjetividad se dibuja y adquiere la cultura de su grupo, se instruye y se educa a las nuevas generaciones, y se moldean las reglas y normas, pero, también, se construyen realidades y se moviliza la trasformación de las existentes.

Así pues, el sujeto contemporáneo, inmerso en la continuidad entre la cultura escolar y la cultura mediatica, no está exento de las posibilidades de percepción y creación que trae consigo el cuadro completo de técnicas, los medios y las modalidades de transmisión y comunicación educativa. La subjetividad actual se ve abocada al uso de diferentes tecnicidades, al manejo de diferentes niveles de memoria y al tratamiento de distintos soportes intergeneracionales de conocimiento e información.

Igualmente, el individuo contemporáneo cuenta con una gran diversidad de nuevos medios de relación social online, como las redes sociales, las aplicaciones de mensajes instantáneos, la interconexión de los videojuegos, entre otros, y sus diferentes instrumentos de tratamiento lingüístico de los mensajes, que sirven como puente y proceso de la manifestación de los contenidos de la estructura psíquica en 
los flujos de la conciencia. Y, sin embargo, las exigencias del tratamiento del conocimiento y la información que traen consigo estas transformaciones han generado en los sujetos latinoamericanos la desactualización de las capacidades perceptivas y las habilidades creativas para leer y escribir la complejidad política y cultural contemporánea.

El sujeto contemporáneo no ha universalizado la cultura letrada, pero el mundo marcha al ritmo de los cambios, movilizados en principio por la integración de los medios con las nuevas tecnologías. Mientras se han suman capas de percepción, creación y participación que trasladan, en gran medida, la producción de sentido a la "cibercultura" y a sus tecnicidades inherentes, se sigue haciendo hincapié en la transmisión oral como bastión para conocer y hacer en el mundo. Además, sin haber pasado el lumbral de la Ilustración, grandes masas se ven inmersas y obligadas, no solo por la cobertura, sino también por la dinámica social que comporta la sociedad mediática, a participar pasivamente en los flujos de la conciencia y la subjetivación cultural y política, a pesar de estar inhabilitados para leerla y escribirla.

Es el desafío que trae la tensión resultante de la imposición y la integración en las diferentes alfabetizaciones, y sus tramas perceptivas y creativas, el que ha llevado al sujeto contemporáneo a inhabilitarse y a distanciarse de decir y actuar en la totalidad de los asuntos humanos. Así las cosas, la salida no es entrar en pugna con los espacios-agencias educativos, ni con las tramas donde fluye y se retrasa la conciencia y se construye la subjetividad; por el contrario, hay que entender y manejar sus exigencias, pues son dimensiones estratégicas de la cultura y la política (Huergo, 2001), posibilidades perceptivas y creativas del sujeto, capas de capacidades e instrumentos sociales que se necesitan manejar.

Entonces, el reto es doble: por un lado, crear condiciones educativas para - mientras nos alfabetizamos en las formas perceptivas y creativas- delimitar la subjetividad y participar del flujo de los significados; por el otro, manejar las tecnicidades necesarias para intervenir, reconstruir, construir o mutar el total de la complejidad de nuestras realidades. En suma, hay que construir una subjetividad ciudadana reflexiva, crítica y dialógica, capaz de manejar las exigencias de la sociedad mediática.

\section{Referencias}

Castells, M. (2006). La sociedad red: una visión global. Madrid: Alianza.

Collado, F. (2008). La influencia de las radios y las televisiones comunitarias en la construcción de la ciudadanía. Ámbitos, (17) , 209-224. 
Barbero, J. M. (1999). La educación en el ecosistema comunicativo. Comunicar, (13), 13-21.

Bauman,Z. (2015). Modernidad líquida. México, D. F.: Fondo de Cultura Económica. Easton, D. (1969). Enfoques sobre teoría política. Buenos Aires: Amorrortu.

Foucault, M. (1976). Vigilar y castigar: nacimiento de la prisión. Buenos Aires: Siglo Veintiuno.

Garcés, V. H. (2014). La radio escolar: el eslabón para la articulación entre cultura escolar y cultura mediática. En Olarte M. (Ed.), Infancias y juventudes latinoamericanas. Manizales: Centro de Estudios Avanzados en Niñez y Juventud, Fundación Centro Internacional de Educación y Desarrollo Humano, Universidad de Manizales, Consejo Latinoamericano de Ciencias Sociales.

Gómez Vargas, H. (2005). El mundo no es suficiente para (re)pensar la radio y las nuevas experiencias mediáticas. UAM-X, (14), 325-333.

Huergo, J. A. y Fernández, M. B. (2000). Cultura escolar, cultura mediática/intersecciones (vol. 1). Bogotá: Universidad Pedagógica Nacional.

Huergo, J. A. (2001). Desbordes y conflictos entre la cultura escolar y la cultura mediática. Nómadas, (15), 88-100.

Huergo, J. A. (1998). Las alfabetizaciones posmodernas, las pugnas culturales y los nuevos significados de la ciudadanía. Nómadas, (9), 49-60.

Kaplún, M. (1998). Una pedagogía de la comunicación. Madrid: Ediciones de la Torre.

Keane, J. (1997). Transformaciones estructurales de la esfera pública. Estudios sociológicos, 15(43), 47-77.

Lechner, N. (2000). Nuevas ciudadanías. Revista de Estudios Sociales, (5).

Obregón, J. S. (2009). Jan Amós Comenio: sujeto triádico y ordenamiento metódico de las prácticas escolares. Revista Educación y Pedagogía, 19(47).

Palacios Mena, N. y Herrera González, J. D. (2013). Subjetividad, socialización política y derechos en la escuela. Magis. Revista Internacional de Investigación en Educación, 413-437.

Pereira, J. M. (2001). Comunicación y ciudadanía. Apuntes para comprender las radios y televisiones comunitarias en Colombia. Signo y Pensamiento, (38), 102-116.

Pierre, L. (2007). Cibercultura. Barcelona: Anthropos. 
Roncagliolo, R. (1997). El futuro imperfecto de la radio. Chasquis, (39), 4-7.

Rueda, R. (2012a). Educación y cibercultura en clave subjetiva: retos para re(pensar) la escuela hoy. Revista en Educación y Pedagogía, 24(62), 155-171.

Rueda, R. (2012b). Sociedades de la información y el conocimiento: tecnicidades, phármakon e invención social. Nómadas, (36), 43-55.

Wallerstein, I. M. (2007). Geopolítica y geocultura: ensayos sobre el moderno sistema mundial. Barcelona: Kairós.

Winocur, R. (Febrero-marzo de 2007). La participación en la radio: una posibilidad negociada de ampliación del espacio público. Razón y Palabra, 12(55). 